\title{
0499 WORKPLACE VIOLENCE NATURE, PREVALENCE AND RISK FACTORS AMONG DRIVERS AND CONDUCTORS IN MAPUTO CITY, MOZAMBIQUE
}

M T Couto*, S Lawoko, L Svanström Correspondence: Maputo and Karolinska Institutet-Stockholm Sweden, Eduardo Mondlane University/Faculty of Medicine, P.O. B0X 264, Maputo/Mozambique 258, Mozambique

\subsection{6/ip.2010.029215.499}

Workplace violence is a worldwide phenomenon. Studies indicate that, physical and psychological violence against workers in the road transport sector is relatively common. This paper provides data on nature, prevalence and risk factors of such violence in the road passenger transport sector in Maputo city, Mozambique. In a cross-sectional survey was examined the nature, prevalence and risk factors for workplace violence in the road passenger transport sector in Maputo, the capital city of Mozambique. A sample of 504 participants was randomly selected from a population of 2618 registered bus, minibus drivers/conductors and taxi drivers. Results indicate that workplace violence, psychological and physical, is highly prevalent among drivers and conductors, with $77 \%$ reporting ever being abused and $64 \%$ being abused in the past 12 month. The most vulnerable groups were illiterate employees, bus drivers and conductors, employees with long experience and holding a supervisory position. In addition, high workload was associated with an increased exposure to workplace violence in the road passenger transport sector in Maputo city. Implications of findings for interventions are discussed. 